Original Research

\title{
Implementation of Chest Compression for Cardiac Arrest Patient in Indonesia: True or False
}

\author{
Rendi Editya Darmawan'1, Untung Sujianto² and Nana Rochana ${ }^{2}$ \\ ${ }^{1}$ Health Polytechnic of Ministry of Health Surakarta, Central Java, Indonesia \\ ${ }^{2}$ Department of Nursing Diponegoro University, Central Java, Indonesia
}

\begin{abstract}
Introduction: The highest cause of death is cardiac arrest. Proper manual chest compression will increase survival of cardiac arrest. The aim of this study was to know the implementation of chest compressions for cardiac arrest patient in Indonesia.

Methods: This study used a descriptive quantitative design. The samples were nurse and code blue team when performing manual chest compression to 74 patients experiencing cardiac arrest. The sample have body Mass Index (BMI) more than 20. Research was conducted in two hospitals in Java, Indonesia. Implementation of chest compression is measured based on depth accuracy. Depth accuracy of chest compressions was assessed based on the comparison of the number of $\mathrm{R}$ waves with a height $>10 \mathrm{mV}$ on the bedside monitor with the number of chest compressions performed. The data were analyzed descriptively (mean, median, mode, standard deviation, and variances).
\end{abstract}

Results: The mean of accuracy of compression depth is $75.97 \%$. The result shows accuracy of compression depth on manual chest compression still under the American Heart Association (AHA) recommendation of $80 \%$, because chest compression rate are not standardized. Chest compression rates are between 100-160 rates/minute, while AHA's recommendations are 100-120 rates/minute. High compression speed causes a decrease in accuracy of chest compressions depth.

Conclusion: The implementation of chest compressions in Indonesia if measured based on accuracy of compression depth is not effective. Nurses and the code blue team have to practice considering the use of cardiac resuscitation aids.

\section{ARTICLE HISTORY}

Received: January 22, 2020

Accepted: December 30, 2020

\section{KEYWORDS}

accuracy of compression depth; cardiac arrest; chest compression

\section{CONTACT}

Rendi Editya Darmawan $\triangle$ ndikners@yahoo.com $\equiv$ Health Polytechnic of Ministry of Health Surakarta, Central Java, Indonesia

Cite this as: Darmawan, R. E., Sujianto, U., \& Rochana, N. (2021). Implementation of Chest Compression for Cardiac Arrest Patient in Indonesia: True or False. Jurnal Ners, 16(1). 13-16. doi:http://dx.doi.org/10.20473/in.v16i1.17508

\section{INTRODUCTION}

Cardiac arrest (CA) is an emergency condition with a high mortality rate, and patient survivors are low (Perkins et al., 2015). The mortality rate of patients due to CA is high. Perkins et al. (2015) and Grunau et al. (2016) reported more than $90 \%$ of CA patients in the UK and North America dying. The incidence of cardiac arrest in Indonesia is unknown. The biggest cause of CA is cardiovascular disease (70\%), so if there are more than 5 million people with cardiovascular disease in Indonesia, CA sufferers in Indonesia are quite high (Darmawan, Sujianto, \& ROchana, 2018).
The external factor affecting CA survivor is the quality of resuscitation (AHA, 2015). The American Heart Association (AHA) (2015) recommends CPR done at a speed of 100 to 120 compression rates per minute. Rescuer must push chest wall with the depth of 5 to $6 \mathrm{~cm}$. Rescuer must allow full chest wall recoil, and to minimize interruptions (AHA, 2015). Rescuer in hospital often do not to do high quality CPRs, especially related to compression rates and depths (Coy \& Schultz, 2015; Hasegawa, Daikoku, Saito, \& Saito, 2014; Idris et al., 2012; Monsieurs et al., 2012; Ruiz de Gauna, González-Otero, Ruiz, \& Russell, 2016). Appropriate chest compression speed, will provide the perfect depth of chest compressions (Monsieurs et al., 2012). 
The chest compression rate affects the depth of chest compression. Monsieurs et al. (2012) concluded that chest compressions were high, resulting in low chest compressive depth. On the other hand, chest compression rate in Indonesia is not standardized (Monsieurs et al., 2012). Darmawan and Oktavianus (2013) reported that the rhythm of rule of five or two syllables has an average chest compression velocity of $125.7 \mathrm{x} / \mathrm{min}$ and the depth of chest compression that reaches $5 \mathrm{~cm}$ is $39.05 \%$, while the rhythm of the rule of ten or one syllable produces chest compression speed $157 \mathrm{x} / \mathrm{min}$, with a chest compression depth that reaches $5 \mathrm{~cm}$ which is $39.27 \%$.

Unstandardized rhythm can decrease accuracy of compression depth (Gauna et al., 2016). Although the nurses and the code blue team have experience in performing chest compressions, in reality the rate of chest compressions taken by the AHA has not been implemented properly. Therefore, it is necessary to study how is the implementation of chest compressions in Indonesia, so that the most effective method of chest compressions can be developed effectively in the future. The aim of this study was to know the implementation of chest compressions for cardiac arrest patient in Indonesia, especially the accuracy of compression depth.

\section{MATERIALS AND METHODS}

This study used a descriptive quantitative design. The researcher determined the number of samples using previous study methods that are sourced from Idris et al.'s (2012) research. Calculation results obtained 74 cardiac arrest patients. The researcher also selected rescuer as respondents using purposive sampling techniques.

The researcher recruited enumerators, and taught them how to calculate the depth of chest compressions. When chest compressions are performed, the screen image of bedside monitor will show $\mathrm{R}$ waves. The researchers and enumerator recorded the number of $\mathrm{R}$ waves with the height more than $10 \mathrm{mV}$ and the number of chest compressions (using hand counters). Then, the number of $\mathrm{R}$ waves with the height more than $10 \mathrm{mV}$ were divided with the number of chest compressions done to determine accuracy of chest compressions.

Data were analyzed by finding descriptive data, such as averages of accuracy of chest compressions, and other data, such as median, mode, standard deviation, and variances, using SPSS 25.

The researcher established inclusion criteria as chest compressions on a solid surface, patients have heart electrical records using bedside monitor, CPR was done by medical personnel who have certified emergency training. Rescuer must have weight more than 20 of body mass index (BMI). Exclusion criteria were patients marked with do-not-resuscitate. The researcher obtained ethical clearance from The Health Research Ethics Committee of Faculty of Medicine, University of Diponegoro (Number :176 / EC / FK-RSDK / IV / 2017). The research was conducted in two hospitals in Java, Indonesia, by asking permission from the director of the hospital. The researcher asked permission from the patient's family with giving informed consent. Researchers and enumerators $\mathrm{w}$ waited for a patient to experience cardiac arrest, with a sign of a code blue call.

\section{RESULTS}

Research results obtained74 patients having cardiac arrest that were given cardiopulmonary resuscitation with complete data, and according to the criteria. The characteristics of people who performed chest compressions are shown in Table 1.

Characteristics of rescuers, as presented in Table 1 , show most respondents have experience more than 10 years in doing chest compressions $(79.8 \%)$. The mean of body mass index of respondents is 23.436, with an intermediate range 21-26.4. All respondents are certified in emergency training. Accuracy of chest compression can be seen in Figure 1.

Based on Figure 1, the accuracy of chest compressions is $29-96 \%$, and the average accuracy of chest compressions is $75.97 \%$. The result of the variance test showed the number 226,769. These data show a high variation among chest compressions. When viewed from the standard deviation of 15.059, it means that the range of variation in chest compression accuracy is quite wide. The median value shows 80.00 , while the mode value shows the number 81 . This condition indicates that most of the implementation of chest compressions is good and above the standard of AHA. On the other hand, some rescuers did not successfully achieve proper chest compressions accuracy.

\section{DISCUSSION}

The implementation of chest compressions for cardiac arrest patient in Indonesia has not been done optimally. This condition is shown from the data that accuracy of chest compressions is $75.97 \%$. The mean of accuracy of compression depth needs to be improved. There is absence of a speed regulator to arrange compression rates making for faster of chest compression rates. Chest compression rates in this study show a range 120-160 beat/minute. Chest compression rates more than 120 beat/minutes cause fatigue in the helper, which, in turn, causes a decrease in strength of compressions, so that the accuracy of compression decrease (Chung et al., 2012).

Chest compressions rate can affect compression depth. Monsieurs et al. (2012) explain that the higher chest compressions rate affects decreased concentration, so that the rescuer cannot control the speed and depth of chest compressions. If we look at the data, mean of accuracy of chest compressions is 75.97\%. This mean is below AHA recommendation, 
Table 1. Distribution of Characteristics' Respondents $(n=74)$

\begin{tabular}{lcccc}
\multicolumn{1}{c}{ Variable (s) } & f & $\mathbf{\%}$ & Mean (SD) & Min-Max \\
\hline Long been a code blue team & 2 & 2.7 & & \\
2-5 years & 13 & 17.5 & & \\
5-10 years & 59 & 79.8 & & \\
> 10 years & & & $21.00-26.4$ \\
Body mass index & 74 & 100 & & \\
Have an emergency training certificate & & & \\
\hline
\end{tabular}

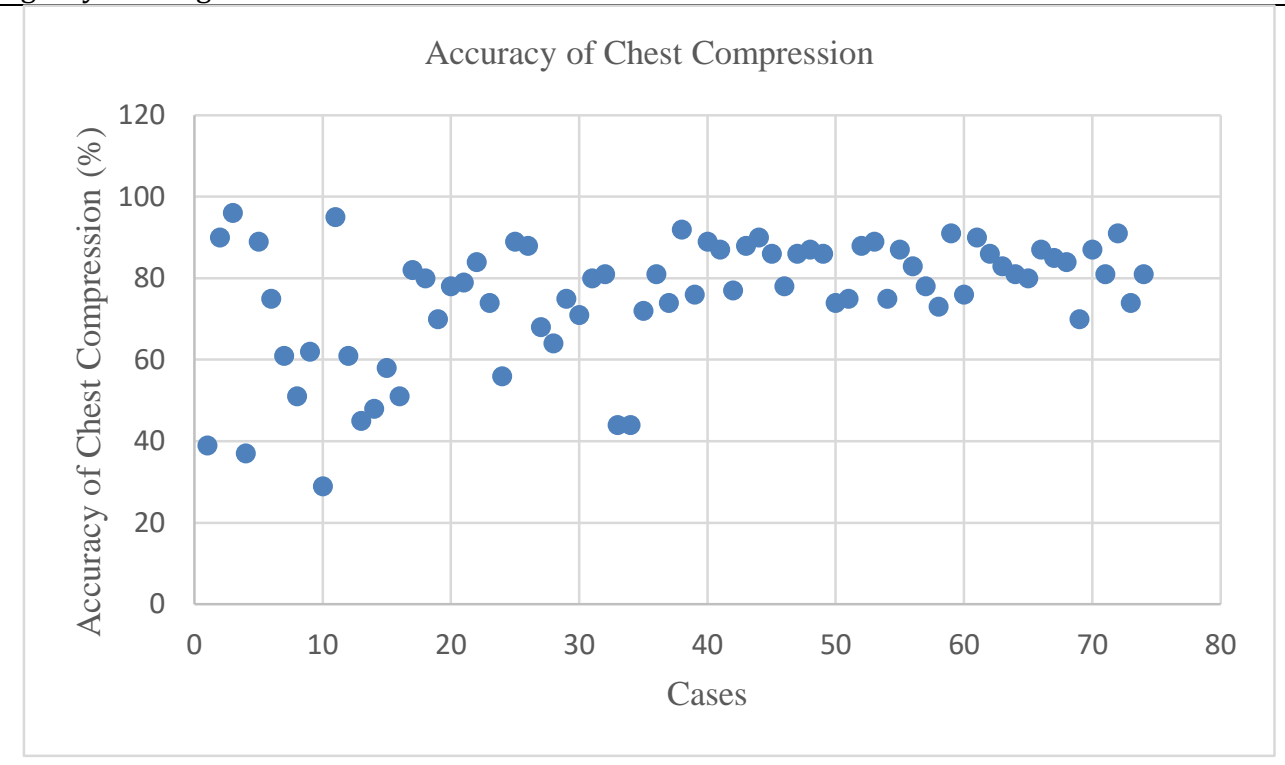

Figure 1. Accuracy of Chest Compression

which is $80 \%$. There needs to be an effort to improve accuracy of chest compressions.

Besides compression rates, weight rescuer factor can also be decisive of compression depth. The heavier rescue makes impact easier to get ideal compressions depth. AHA explains that the high position of the bed will affect the accuracy of chest compressions (Gauna et al., 2016). Ideally the position of the bed is adjusted to the height of the helper. Jantti, Silfvast, Turpeinen, Kiviniemi, and Uusaro, (2009) explain the surface under the patient must be firm, because it is a counter of pressure exerted on the patient's chest.

The accuracy of chest compressions has an impact to return of spontaneous circulation (ROSC) and survival with good neurological function. Accuracy of chest compressions is determined by chest compression rates, weight of rescuer, surface under the patients, as well as the number and duration of disturbances in compression (Grunau et al., 2016). Sometimes, we must stop compressions due to attaching intubation, or other tools. In most studies, chest compressions rate with 100-120 beats per minute is associated with an increased survival rate, and lower than 100 beats per minute is associated with a decreased survival rate. The rescuer should begin to adjust the compression rate and minimize distraction during compression (AHA, 2015).

During CPR, the rescuer must provide effective compression at speeds of 100 to $120 \mathrm{x} /$ minute, accuracy of chest compression higher than $80 \%$, and the appropriate depth, minimizing the number and duration of disturbances in chest compressions. Additional components of high-quality CPR include allowing full chest recoil after each compression and preventing excessive ventilation (Graham et al., 2015). Accuracy of chest compression must be increased to improve survival of cardiac arrest.

Other than compression rates, the weight of the rescuer is an important factor in the compression depth (Hasegawa et al., 2014). Respondents of this study have body mass index mean 23.436, with an intermediate range 21-16.4. It is ideal body for a rescuer to perform chest compressions. Jäntti et al. (2009) find that bed height affects maximal compression forces, and affects accuracy of compression depth. Dellimore and Scheffer (2012) showed the surface under the patient may affect the cardiopulmonary resuscitation (CPR) quality. The limitation of this study is that there is not a large number of samples. In addition, researchers do not limit body weight in cardiac arrest patients, because body weight will affect the amount of pressure required for chest compressions.

Another factor affecting the accuracy of chest compression depth is the training gained. This study shows that all executor chest compressions are certified, but, when viewed from variations in the accuracy of chest compressions is 29-96\%, then there is an abnormality. Körber, Köhler, Weiss, Pfister, and Michels, (2016) reported differences in the quality of chest compressions between students and experienced medical personnel. It can be concluded that, when the reservoir is homogeneous, the 
accuracy should be the same. The researcher is of the opinion that this occurs because there is no continuous renewal of science, so it is possible to forget the principles of chest compressions.

\section{CONCLUSION}

The implementation of chest compressions for cardiac arrest patient in Indonesia, based on accuracy of compression depth is lower than standard. Helpers of cardiac arrest must control chest compression rate to improve accuracy of compression depth. Future research can increase the number of samples and homogenize the type of ward.

\section{REFERENCES}

AHA. (2015). Highlights of the 2015 American Heart Association guidelines update for CPR and ECC. In American Heart Association.

Chung, T. N., Kim, S. W., You, J. S., Cho, Y. S., Chung, S. P., \& Park, I. (2012). A higher chest compression rate may be necessary for metronome-guided cardiopulmonary resuscitation. The American Journal of Emergency Medicine, 30(1), 226-230. https://doi.org/10.1016/j.ajem.2010.11.026

Darmawan, R. E., Sujianto, U., \& ROchana, N. (2018). Effects of neo automatic code on the accuracy of chest compression depths in cardiac arrest patients. Hiroshima Journal of Medical Sciences, 67.

Darmawan R E, \& Oktavianus. (2013). Pengaruh kompresi dada berdasarkan rule of five terhadap kedalaman dan frekuensi kompresi dada. Jurnal Kesehatan Kusuma Husada, 4(1), 47-56.

Dellimore, K. H., \& Scheffer, C. (2012). Optimal chest compression in cardiopulmonary resuscitation depends upon thoracic and back support stiffness. Medical \& Biological Engineering \& Computing, 50(12),

1269-1278. https://doi.org/10.1007/s11517-012-0963-z

Gauna, S. R. De, González-otero, D. M., Ruiz, J., \& Russell, J. K. (2016). Feedback on the rate and depth of chest compressions during cardiopulmonary resuscitation using only accelerometers. Plos One, 11(3), 1-17. https://doi.org/10.1371/journal.pone.0150139

Graham, R., Coy, M. A. M., \& Andrea M Schultz. (2015). Strategies to improve cardiac arrest survival a time to act. Wasington DC: the national academies press.

Grunau, B., Reynolds, J., Scheuermeyer, F., Stenstom, R., Stub, D., Pennington, S., ... Christenson, J. (2016). Relationship between time to ROSC and survival in out of hospital cardiac arrest ECPR candidates: when is the best time to consider transport to hospital? Prehospital Emergency Care : Official Journal of the National Association of EMS Physicians and the National Association of State EMS Directors, 20(5), 615-622. https://doi.org/10.3109/10903127.2016.11496 52

Hasegawa, T., Daikoku, R., Saito, S., \& Saito, Y. (2014). Relationship between weight of rescuer and quality of chest compression during cardiopulmonary resuscitation. Physiological Anthropology, 33(16), 1-7.

Idris, A. H., Guffey, D., Aufderheide, T. P., Brown, S., Morrison, L. J., Nichols, P., ... Nichol, G. (2012). Relationship between chest compression rates and outcomes from cardiac arrest. Circulation, 125(24),

3004-3012. https://doi.org/10.1161/CIRCULATIONAHA.111. 059535

Jäntti, H., Silfvast, T., Turpeinen, a, Kiviniemi, V., \& Uusaro, a. (2009). Quality of cardiopulmonary resuscitation on manikins: on the floor and in the bed. Acta Anaesthesiologica Scandinavica, 53(9), 1131-1137. https://doi.org/10.1111/j.13996576.2009.01966.x

Körber, M. I., Köhler, T., Weiss, V., Pfister, R., \& Michels, G. (2016). Quality of basic life support : a comparison between medical students and paramedics. Journal of Clinical and Diagnostic Research: JCDR, 10(7), OC33-7. https://doi.org/10.7860/JCDR/2016/19221.819 7

Monsieurs, K. G., De Regge, M., Vansteelandt, K., De Smet, J., Annaert, E., Lemoyne, S., ... Calle, P. a. (2012). Excessive chest compression rate is associated with insufficient compression depth in prehospital cardiac arrest. Resuscitation, 83(11), 1319-1323. https://doi.org/10.1016/j.resuscitation.2012.07. 015

Perkins, G. D., Lall, R., Quinn, T., Deakin, C. D., Cooke, M. W., Horton, J., ... Gates, S. (2015). Mechanical versus manual chest compression for out-ofhospital cardiac arrest (PARAMEDIC): a pragmatic, cluster randomised controlled trial. Lancet (London, England), 385(9972), 947-955. https://doi.org/10.1016/S0140-6736(14)618869

Ruiz de Gauna, S., González-Otero, D. M., Ruiz, J., \& Russell, J. K. (2016). Feedback on the rate and depth of chest compressions during cardiopulmonary resuscitation using only accelerometers. PloS One, 11(3), e0150139. https://doi.org/10.1371/journal.pone.0150139 